\title{
Hidden Hands: An Institutional Force in Political News Translation
}

\author{
Hamza Ethelb (Corresponding author) \\ Faculty of Languages, University of Tripoli, Libya \\ Email: h.ethelb@uot.edu.ly
}

Received: 09/02/2020

Accepted: $15 / 05 / 2020$

Published: 20/05/2020

Volume: 1 Issue: 1

How to cite this paper: Ethab, H. (2020). Hidden Hands: An Initial Force in Political News

Translation. Journal of Critical Studies in Language and Literature, 1(1), 1-8

https://dx.doi.org/10.2525/jcsll.v.1n.1.2020 P.1

Copyright (C) 2020 by author(s) and Global Talent Academy Ltd. This work is licensed under the Creative Commons Attribution International License (CC BY 4.0).

http://creativecommons.org/licenses/by/4.0/

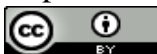

\begin{abstract}
This article explores translation in news institutions. While being heavily relied on by media organizations, translation is rarely acknowledged. Translation is deeply interwoven with news in that it is used to employ ideological tendencies and political agendas. This study investigates the powerful role of media institution as a force that intervenes in producing news reports. It uses a questionnaire and interviews to see the influence of editors in the translation of news texts. For this purpose, the views of 21 news translators, journalists and news were surveyed to infer the role of institutions in translation. The study looks at this role from different angles including translator training, instructions given to translators, textual alterations, and policies of news institutions. The findings indicate that intervention by the editors and producers on translation is taking place. The interview participants tend to agree with the intervention of the institution. The questionnaire respondents agree with the statement that translators are given instructions to use specific terminology but disagree with a statement that they have to comply with the policies of the institution.
\end{abstract}

Keywords: Editorial Guidelines, Ideology, Institution, Instructions, News Translation

\section{Introduction and context}

The exponential growth of Translation Studies as an interdisciplinary field highlights the significance of global communication and the role of the news media in disseminating news stories. Translation is a key factor in the process of transmitting information across cultures and into other languages. Valdeón (2020, p. 332) states that "the role of translation in news writing can indeed be traced back to the birth of journalism"; although, it only gets mentioned "in passing" in journalism. News translation is generally connected with the discourse and ideology of the media organizations. In this context, translators may face considerable textual or institutional constraints. Thus, discourse analysis is crucial in analyzing media texts, including news articles, because it allows us to reflect on the social and discursive practices as well as the political ideology (Schäffner, 2015) of an institution.

In her article Political Discourse Analysis, Schäffner (2004) offers a different account from the early Translation Studies. She states that "Modern Translation Studies is no longer concerned with examining whether a translation has been 'faithful' to a source text (the notion of 'equivalence' is almost a 'dirty' word now)" (Schäffner, 2004, p. 136). Instead, she continues, the focus now is on social, cultural and ideological aspects as well as the external politics surrounding the translation act. It goes without saying that human interaction involves language. However, in linguistic interaction, socio-cultural, historical, ideological and institutional issues may determine the discourse of an organization, as well as the textual structure of that discourse (Schäffner \& Bassnett, 2010). 
It could be argued that the consensual view towards journalism as a truth-seeking activity and journalists as the eyes and ears of the public (Machin, 2008) may no longer have credence. In fact, it is quite understood in the political arena that by tracing the sources of news reports, especially those resulting from translation, one could come across surprising findings in their content, resulting from the manipulation accompanying their production (Schäffner, 2004). The way translations are made in news agencies appear to be adopting different strategies. However, it is worth stating here that most of the political studies on translation have taken their data from news articles to exemplify and operationalize their concepts, without looking into the nature of translating news.

Therefore, the objective of this paper is to explore the socio-political practices of news translators in order to shed light on the impact of the media institution on the translation process, and to see whether the ideologies' adopted by media institutions are impinged on the translation activities. This study is of important significance in terms of helping understanding the role of media institutions when it comes to translation as it expresses the views of news professionals who carry out translation activities on a daily basis.

News fundamentally functions within a global sphere. News organizations are undoubtedly competing in the production, consumption and circulation of information. According to Cronin (2011), such activities are organized on a global scale between different global agents; organizations from all over the world function in different languages, which have created an increasing demand for mediation and communication through translation.

This is particularly true in the case of the Arab Spring as social media networks helped in coordinating events and protests, not to mention the role of translation in reporting the local news to the global audience (cf. Castells, 2012). The leading role of Aljazeera, for instance, in covering the events on a daily basis has been acknowledged by Castells (2012). This reflects the way languages are involved in transferring knowledge and information worldwide. Translation is gaining an increasing demand in news networks. Similarly, the production process of global news requires mediating cultural differences, a role which is central to translation (Bielsa \& Bassnett, 2009). News networks helped the spread of ideology not through geographical or chronological elements but rather through different kinds of social media means (Calzada-Pérez, $2003)^{1}$. The mainstream media as well as the social media could be argued to have fostered certain beliefs and were able to feed them into their daily production for political purposes.

This research, therefore, interests in the practices of translating news texts and the duties entrusted to news translators in representing reality. In investigating this process-oriented translation and tracing the pathways of producing translated news articles, a questionnaire was delivered and interviews were conducted with news translators who translate news on a daily basis. The questionnaire and the interview questions have been specifically designed to infer ideological tendencies in news translation and the influence and intervention of institution or other superior and senior staff in the process. The survey participants had to meet the following criteria:

- They have been involved in writing news articles in different languages.

- They function as sub-editors- or editors-in-chief in a news organization.

- $\quad$ They are specialized in political news, not economic or sports.

A convenience sampling technique has been adopted in this study. This is due to the fact that news translators and journalists were reluctant to take part in the research. Participants were given a Participant Information Sheet before and along with the questionnaire, and prior to the interview, which included a detailed explanation of the study. Williams \& Chesterman (2002, p.24) contend that in a study that investigates an institution and policies taken to promote a discourse through translation, a combination of a questionnaire and interviews can help broaden our understanding of the "working process of translators" in terms of the practices used. In other words, interviews and questionnaire offer access to the thoughts and beliefs of media professionals towards translation, and how translation is conceived and conducted (Saldanha \& O'Brien 2013). Furthermore, this study explores whether news agencies perceive translation as a separate job, or whether translation skills are a prerequisite in the job of journalists.

The interview participants were from three media organizations: Aljazeera (1 participant), BBC (1 participant) and Sky News Arabia (2 participants). They have a considerable experience in translating news and also meet the criteria set above. One of them is a sub-chief editor who has news translators working under their instructions. In addition to translation, they were involved in other forms of journalistic work, which is what made their contributions to this study valuable.

On the other hand, the questionnaire respondents were 17 and from a number of Arab and international news organizations. They are involved in news translation and journalistic work on a daily basis. Their practical experience in translating news ranges from 1 to 35 years. Some work for local news agencies and others have worked for or have been trained by international news agencies, such as Aljazeera, AFP or Reuters. The questionnaire respondents are working in the following media networks: Asia Digital Media Group, Libyan News Agency, Libyan Herald, Al-Madina Multimedia Center, Middle East Online, Italintermedia, Asahi Shimbun, Radio Lumen, Sky News Arabia, BBC, AFP, Aljazeera, BBC Monitoring, Jordan Times, and Al Akhbar Daily News. Although some of them have no formal journalistic education or translation degree, they all have news translation training and/or considerable practical experience in the field.

This paper explores the issue of institutional influence and role in translating political news from four angles. First, it begins by discussing translation training in news organizations and whether it is perceived crucial to have translation training before embarking on news translation task or not. Second, it surveys whether news translators or journalists are given instructions on their way of producing texts or not. By instructions, I mean that they are told and forced to use specific 
terminologies and avoid others. Third, it moves on to discuss the textual alterations occurring on translated texts and to what extent these changes can be done. Finally, the study investigates an important aspect of writing news reports which is the institutional policies - the guidelines of producing news stories - to see the extent of intervention happening on translated texts by news editors or producers.

\section{Translation training in news}

Translation is an indispensable process in news writing, and this is why global and local news organizations employ journalists who have more than one language. It is often considered that translators do not possess the skills needed for journalistic jobs, but it is an integral part of the journalist's tasks to be able to translate, non-literally (Bielsa \& Bassnett, 2009). The most important aspect in news writing is the content, which should be written in a journalistic style; the author's style should be reduced to the minimum and they should focus on the fluency of the news text (ibid). This also appears to be consistent with the journalistic practices which require more visible meanings of the text itself regardless of how they were rendered. Hence, news rendition encompasses practices that have not been profoundly investigated by translation scholars, albeit, as reported by Bielsa \& Bassnett (2009), entry tests for journalists who desire to work for Reuters and AFP are tests in translation, or to be more specific, in news translation. An important factor implied in this procedure is that news-style reporting is more essential than faithfully adhering to the source text. Participant 3 (2016) who was interviewed for this study said that "I am not a translator, but I am a journalist who can translate". This statement shows how translating and news writing are carried out in news agencies. The statement indicates that the role of translation is largely unacknowledged.

Figure 1 below illustrates the beliefs of questionnaire respondents who seem to agree that one does not need to be a translator to work for a news organization as far as they can write in the target language. Of course, it is essential to be able to write news reports in the target language, but translation has to come in the way as in this case the journalist is not working in their mother tongue. 5 respondents disagree with it and 2 were undecided. Participant 1 (2016) in the interview differentiates between the translator and the writer. He mentions that they have translators/interpreters in their organization. When the term 'translator' is used, it only refers to the interpreter who interprets live conferences and events. He continues to say that we have "the writer reporters who, as a part of their job, translate wires and news stories and rewrite them into Arabic". These writer reporters are not called 'translators'. Hence, there are two different jobs. The translator always refers to the interpreter in media situations. The journalist who works on a document translation is not a translator - it is the news writer or the writer reporter. Participant 1 (2016) adds that 'translation, for me, was just an automatic process.'

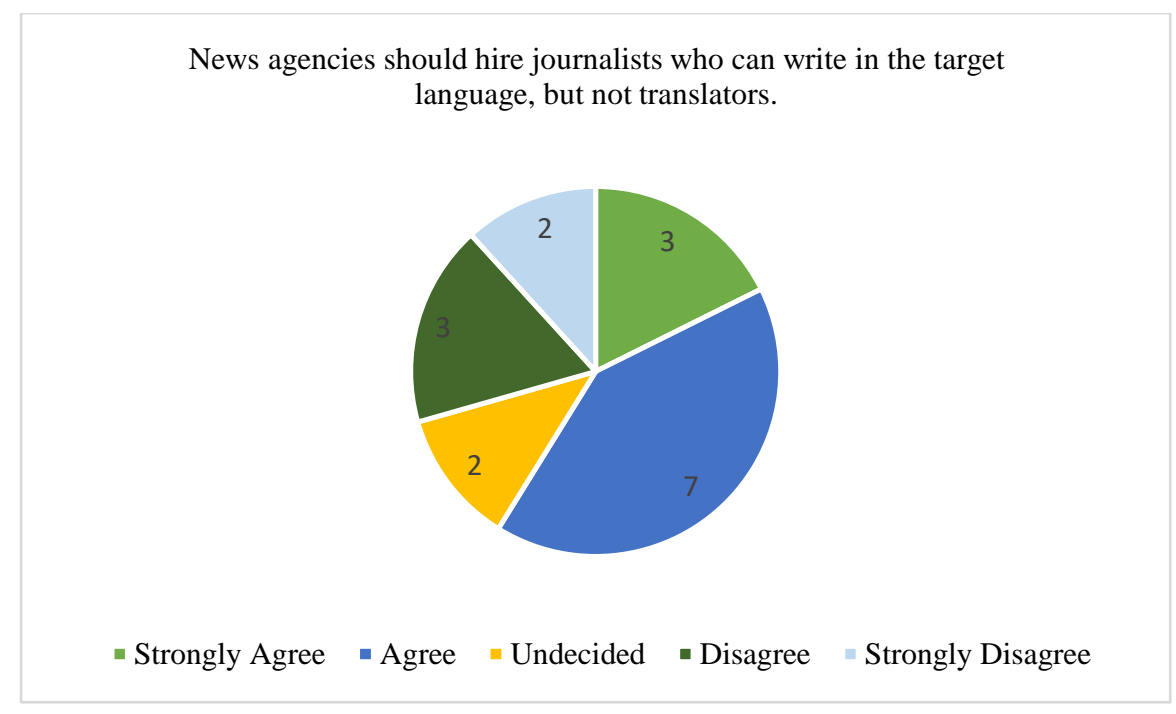

Figure 1. Participants' view of whether to hire writers or translators

Translators are always involved in this process, although they would identify themselves as journalists (Tsai, 2005). The role of a news translator is somehow ambiguous due to the nature of the process and the people involved in it. First, there are the 'fixers', local people who help international journalists establish contacts in areas where they have no local access and mediate between the locals and journalists (Palmer \& Fontan, 2007). A good example of fixers is the Iraqi locals who helped Western journalists during the US invasion of Iraq in 2003 (ibid). Second, the journalists themselves, who are sometimes conducting field reporting while engaging with locals in compiling eye-witness accounts and then translate them for the purpose of dissemination (Orengo ,2005). Finally, the editors in news organizations, who work with journalists in producing news articles, are also influencing the production of a news text by conducting a process of 'transediting'. This is a term 
proposed by Karen Stetting (1989) (cited in Bielsa \& Bassnett, 2009) to account for the grey area between translating and editing.

Bassnett (2006, pp.5-6) reports that those people involved in interlingual news writing prefer the term "international journalists" to news translators. This is attributed to the absence of translator training programmes specifically designed to tackle news translation. The focus in news training is on the journalistic style of writing and reporting rather than translating as traditionally perceived in Translation Studies. The lack of news translator training in media institutions has resulted in radical textual shifts or alterations to the target texts.

\section{Textual changes}

Six out of seventeen of questionnaire respondents seem to be undecided about whether textual changes can occur or not upon instructions of the news producer. In addition, six respondents disagree with this statement, including one who strongly disagrees with it. Five respondents agree with the changes to happen, as shown in Figure 2. On the one hand, textual changes can be made for stylistic conventions and explication. Participant 1 (2016) in the interviews states that they add information to their translation only when they think that "the news story is not understandable. It needs, may be, a historic background or any extra information that will make it clearer to the audience." This is one reason for news writers producing texts out of translation to change the target text. Other reasons include deletion of unnecessary or repetitive information. It is true that the responses were almost even in terms of textual changes, but in a study (Ethelb, 2019) I demonstrate that textual changes are happening on a large scale. Further, Erzurumlu (2019) mentions that textual alterations might occur as a result of following the editing guidelines of a news institution.

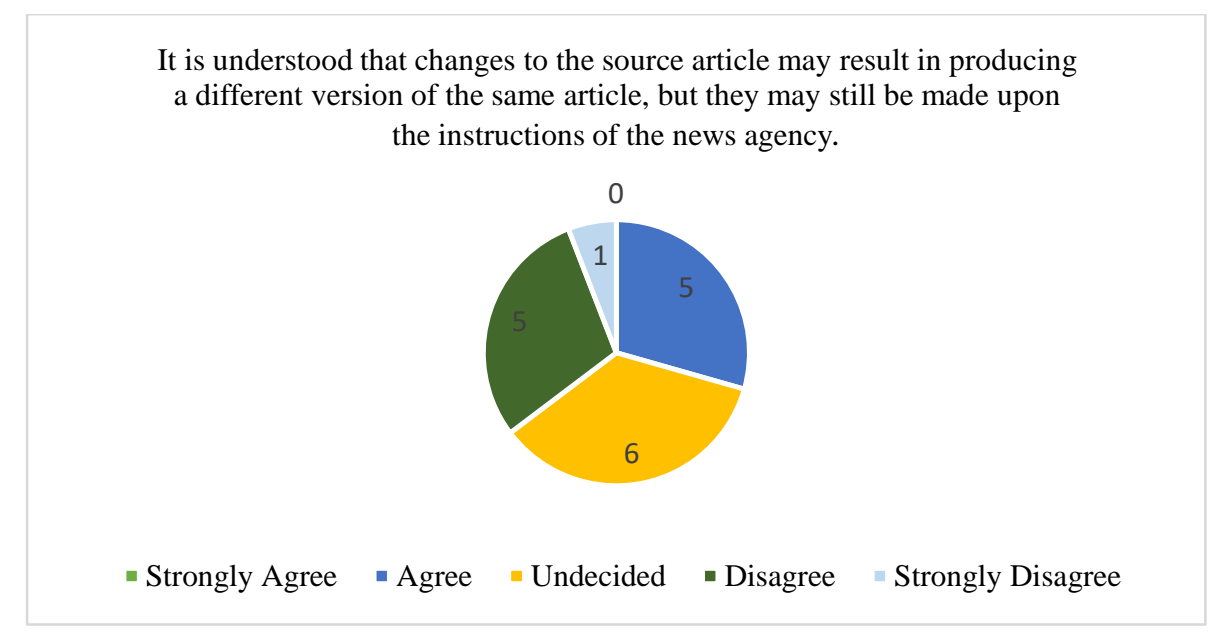

Figure 2. Whether textual changes are made upon instructions of news agency

It is in this context that translators employed in news organizations have, in fact, become journalists and follow journalistic conventions in their rewritings of news stories. Translators find themselves in a position where they need, while translating, editing, selecting, and prioritising segments of information over others, "to be truthful to the audience" (Participant 3, 2016). Put simply, news translators need to appropriately tailor their work with journalistic devices to affect readers. Tsai $(2005$, p.148) asks a critical question about the role of the news translators. Being a news translator herself but holding a job title "Writer in the International News Center", she asks "Are we rewriting the main text in another language or translating it or a little bit of each at the same time?". Rewriting obviously involves manipulating the original texts to make them suit the ideological interests of the initiator of the translation or "the dominant ideological and poetological currents of their times", as Lefevere $(1992$, p.8) puts it. The translation element in news cannot be suppressed or minimally reduced; it should be understood within a translational framework according to the practices occurring in the text. Writing news on the basis of one language and then adapting it into another is still an act of translation. Indeed, the process of news translation implies a task of transformation; that is, information is designed to meet the needs of a new audience (Bielsa \& Bassnett, 2009).

On the other hand, political news can incur a degree of maximum alterations to conform to the political ideologies of the news organization. Participant 2 (2016) from Aljazeera, specifically speaking on news regarding the Arab world, states that "translation is a victim of politicization of many issues in the Arab world". Translation is a tool that news networks employ to embed their beliefs, agendas and ideologies in their products. The content of a text and of how language is used reflects 
ideology at different levels. By way of illustration, translators of news tend to have a degree of freedom which can be reflected in their lexical and syntactic selections that indicate ideological work. Nominalization, for example, is used to conceal the agent. It is a device used locally in texts, but to serve global objectives such as the expression of "alienation" and "powerlessness" (Hatim \& Mason, 1997, p.25). Van Leeuwen and Wodak (1999) seem to endorse this view by stating that where actual facts and processes are replaced by abstracts and generalizations, this is a sign that there is ideological work being done. In line with this, Hatim and Mason (1990) point out that the choice of a word demonstrates the discursive processes at work which reflect the ideological position of the users.

A case in point is Bell (1991, p.66), who writes that "much of the world's news undergo a process far more radical than editing within the same language. Translation between languages is a major language function of the international agencies". Again, textual interventions depend on the extent that a target text should represent the news agency's political views. Textual interventions seem to be high where the author's style is maximally lessened to accentuate stylishly, politically, and ideologically journalistic practices.

\section{Instructions to produce texts}

Fowler (1991, p.4) argues that news "is not a value-free reflection of facts" and that "[a]nything that is said or written about the world is articulated from a particular ideological position" (1991, p.10), and the questionnaire responses presented in Figure 3 seem to endorse it. Nine of the seventeen respondents to the questionnaire agree that translators should be given instructions to use specific vocabulary and avoid others. Participant 2 (2016) interviewed for this study from Aljazeera states that "most of the media outlets have their own terms either verbally or written and they ask their staff to use them". He offers examples regarding the uprising in Syria. He says "we say this is militia, we do not say that it is 'جماعة مسلحة' (armed group). In the Egyptian context, we say 'الرئيس الشرعي' (the legitimate president) for President Mohamed Morsi" (Participant 2, 2016). Aljazeera says 'انقلاب' (the coup) for the 30 June uprising that happened in Egypt in 2013. Translators are instructed to use these terms even if the source does not literally articulate them.

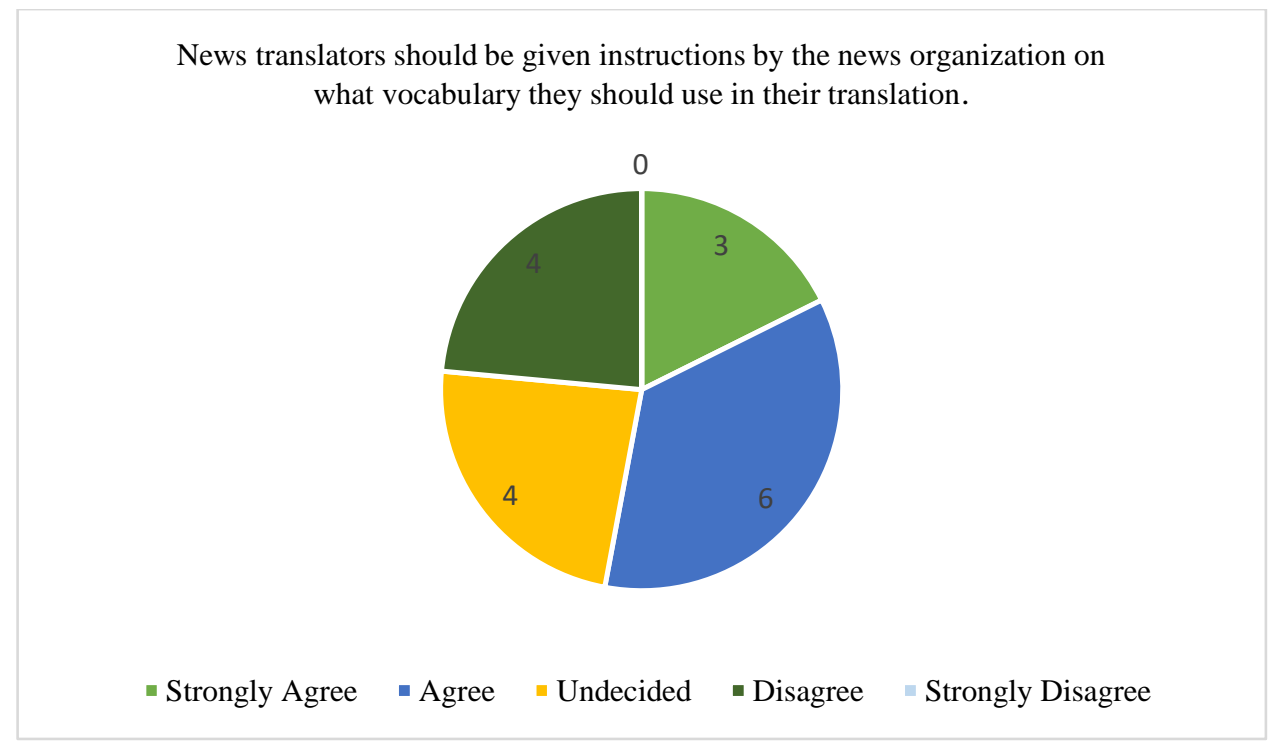

Figure 3. News translators should use specific vocabulary and avoid others

Translators are sometimes instructed to use specific terms and avoid others. Texts may be made inaccessible to the public of a given society if they do not conform to the official ideology of the political party in power. The lexical choices of news translators reflect the strategic use of political concepts a particular ruling party. Participant 3 (2016), an Egyptian BBC journalist who was interviewed for the purpose of this research, adds that "any translator will have a senior editor who will revise their work" to make sure it complies with their political and ideological preferences. Due to the sensitivity of the topic which discusses ideological and institutional roles in translating news, Participant 3 (2016) felt uncomfortable with the questions by denying any intervention from either the news editors or the policies. Participant 4 (2016) also agrees that

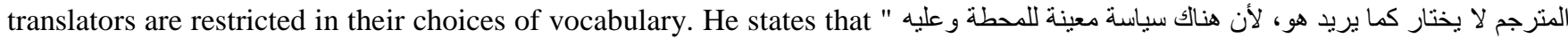

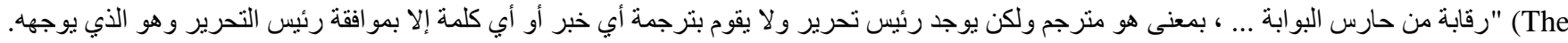
translator does not choose as he likes, because there is a specific policy for the news organization and he is censored by the 
gatekeeper ..., meaning he is a translator, but there is an editor-in-chief. The translator cannot translate any news or a word unless he has approval from the editor-in-chief, who directs him). It can be discerned in this statement that translators of news have lesser freedom in terms of their choice of vocabulary. Other macro issue that is ballooned from such terminology limitation is the policy of news institutions, which discusses the intervention from a broader point of view.

\section{Institution's policy}

News agencies have always been said to serve certain governmental institutions or political parties. In Egypt, for example, media institutions have always been under the influence of the successive governments and controlled by the party in power at a time (Mohammed \& Gunter, 2013). Regardless of pure linguistic approaches, translation is "ultimately political" (Álvarez \& Vidal, 1996, p.1). Álvarez and Vidal argue that the study and practice of translation involve examination of power relations and power structure in a given society. Translators are said to be able to create the context in which receptors see a text. Hermans (1996) states that translating is a matter of manipulating a source text so that target text readers would comprehend it in a way intended by the translator, or in the case of news by the news institution or the commissioner of the translation act. Álvarez and Vidal (1996) demonstrate that the choice of particular vocabulary over other options, or the emphasis on some linguistic element that a given political institution advocates or obfuscates, is reflected in the political implication intended in the text.

If we examine the statement in Figure 4, it is clear that ten respondents out of seventeen disagree with it. However, six agree with it and one respondent is undecided. In discussing the editorial guidelines with the interviewees who were more outspoken than those in the questionnaire, Participant 1 (2016) states that "of course, we have an agenda, but the most important thing is to remain objective and to remain balanced as much as you can". He ties the dissemination of their agendas to objectivity and balance - a task that is difficult if not impossible to achieve. Objectivity means that one needs to stay neutral and take a back step and present both views. Agenda in the political context refers to political views that a news organization pumps huge amount of money to get them in their written and spoken materials.

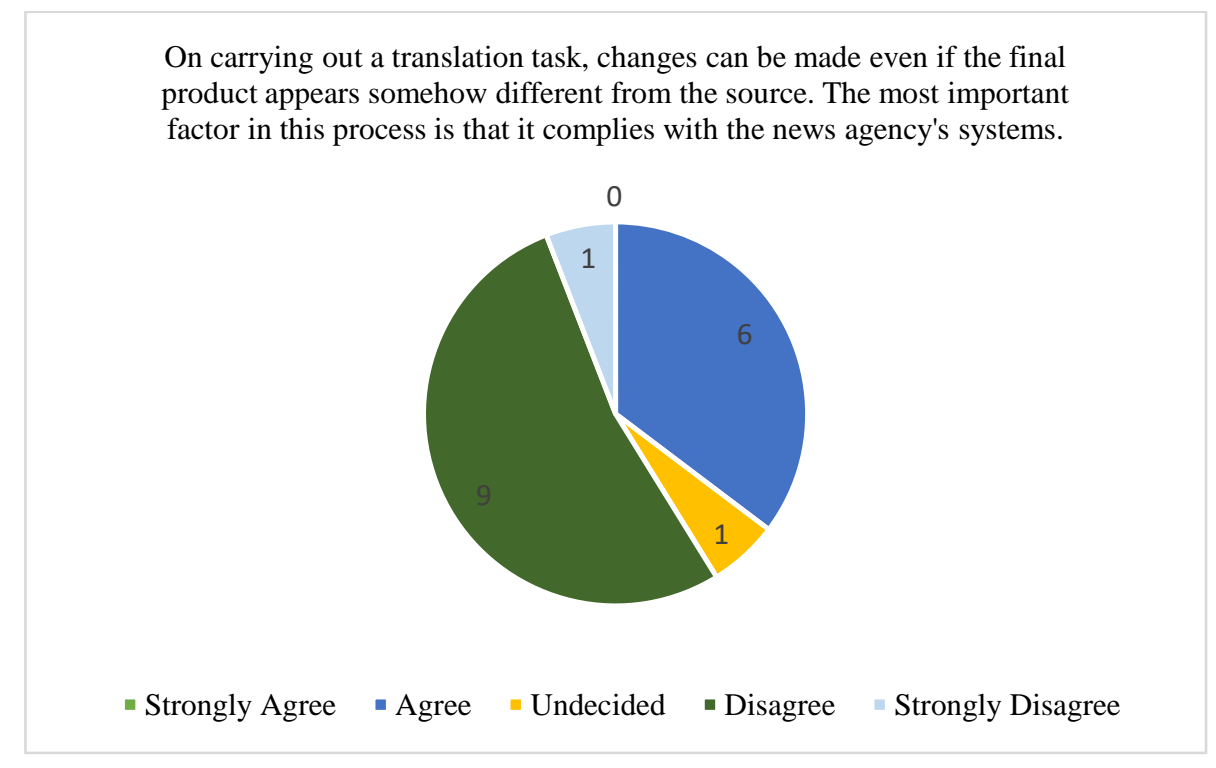

Figure 4. News products compliance with agency's policies

Media institution, according to Hatim \& Mason (1990), should be assigned equal emphasis to the textual intervention because it influences the production of utterances $(\mathrm{ibid})$. Translation Studies has not forgotten to assign such an importance to the concept of institution. In this context, media institutions make changes that are not necessarily geographical or cultural, but can be politically or ideologically oriented. Participant 1 (2016), a sub-editor in Sky News Arabia, states that "there is an editorial meeting every month that filters any specific guidelines". In the meeting, he continues "we update a list of terminology and discuss those terms. Of course, we discuss what to use and what each term means and connotes to if we use it". Hatim and Mason (1990) argue that the choices of text producers serve their own communicative ends and that of the institutional settings in order to influence linguistic expression and that this will affect the text-type focus and in turn will force changes on the structure of the text. Studies of the role of institution and its impact on translation products have been of a greater interest in Translation Studies. Davidson (2000), for example, has studied the role of interpreters in the health care system in the USA by means of physician-patient interviews and observation, and has found that interpreters have an active role and act as informational gatekeepers who keep the interview between the physician and the patient on track. 
Hence, Koskinen (2000) argues that it is necessary to study the institutional constraints affecting a translation task. This is of paramount importance when handling news translation since the process is highly influenced by the system and the overall policy of news agencies. Participant 2 (2016) from Aljazeera summarizes the influence of institution into "the unseen policies". He clarifies it by adding that "the so-called ghost policy of the media. It is a ghost because it is unseen, even in some types there is a kind of exaggeration in taking this side or that side. It even could be harmful to the credibility of the media". He describes the policy as a ghost because it is in the "atmosphere", it is not told or written, as he puts it - one learns it from the surroundings. By looking at Aljazeera Code of Ethics, for example, one would find terms such as honesty, courage, fairness, balance, independence, credibility and diversity (Ethelb, 2019, p.31). In addition, they state that the network is presenting "diverse points of view and opinions without bias and partiality" (ibid). But it appears to be completely the opposite, as argued by Aljazeera journalist in the interview.

Likewise, Hatim and Mason (1990) explain that the social institution is very important in the translation process. It is crucial for the translator, they argue, to consider the beliefs, perceptions and attitudes of the source and target languages "members" (ibid, p.86). The power and status of the social institution influence the production of an utterance - or a news item in the case of this study. As a matter of fact, studies in this regard have been conducted by Fairclough (1995), who notes that lexical selection and lexicalization which emerge from ideological differences have almost always been a result of institutional practices. The institution's policy is always the hidden hand and the force that gears a product to a particular end.

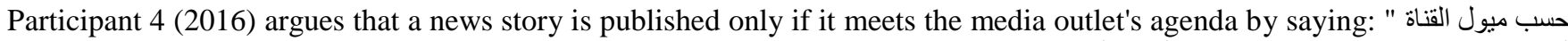

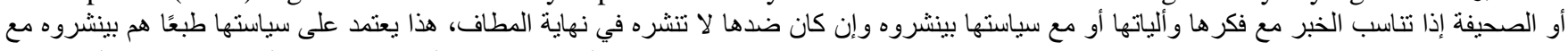

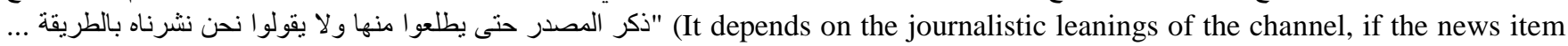
conforms to its idea, mechanisms or polices, it will publish it. If it is against them, it will not publish it at the end. It depends on its policies, of course. It will publish the news item with the source included, to be safe, so that nobody says the channel published it the way it likes). In such contexts, news articles cannot be said to have been mistranslated as media institutions highly contribute in shaping many of the international relations and audiences' opinions (Zanettin, 2016). Translation is a political weapon used to endorse particular points of view, encourage actions, and justify ends ( $\mathrm{ibid}$ ).

\section{Conclusion}

To conclude for a text to be transformed within a news context, it goes through several stages. First, it is rewritten, then it is checked and corrected. After that, a process of modification is conducted in order for the text to meet the spatial constraints. Finally, it is polished up and prepared for publication. Of course, such operation is carried out within an institutional context and it evokes further investigation. This article mainly explored the influence of institution on the intricacies of producing a news product out of translation by looking at four areas: translator training, instructions to produce news texts, textual changes, and institution's policy. Translation in news is not a matter of linguistic act or mere cultural equivalence. It is a regulated discourse that follows certain patterns to embed, at the same time to spread, politically-oriented beliefs forced by institutions. It does not matter if the news translator is highly competent or not. It is that they have to strictly follow the editorial guidelines of a news organization, as per the interviews. However, this was not confirmed in the questionnaire. News translators do not get training of translating professionally, they get training on writing stylistically by adhering to the journalistic conventions of producing news stories. All surveys participants agree that they are given instructions to use specific words of political contextualization and not to use others.

Translation in news outlets is of paramount significance to the point that it is sometimes very challenging to write a news story without resorting to it. Translation in media context is perhaps more significant than any other tool that news organizations use to propagate a specific ideological stance. Some of the questionnaire respondents surveyed in this study do not seem to be articulate in highlighting the important role of the editors and producers to check and approve a news product for publication. However, the interview participants were more expressive in stressing the intervening role of institutions' policies. Translation in news seems to be ideologically mediated and political manipulated. It is a victim of politicization that there are no clear guidelines on how a translation work can be achieved in politically disputed regions.

\section{References}

Álvarez, R. \& Carmen-Africa, M. V. (1996). Translation, power, subversion. Clevedon: Philadelphia, Multilingual Matters. Bassnett, S. (2006). Introduction. In K. Conway \& S. Bassnett (eds.) Translation in Global News: proceedings of the conference held at the University of Warwick, 5-7. University of Warwick.

Bell, A. (1991). The language of news media. Oxford and Cambridge: Blackwell.

Bielsa, E. \& Bassnett, B. (2009). Translation in global news. London and New York: Routledge.

Calzada-Pérez, M. (ed.) (2003). Apropos of Ideology: Translation Studies on Ideology - Ideologies in Translation Studies. London: Routledge.

Castells, M. (2012). Networks of outrage and hope: social movements in the Internet Age. Cambridge and Malden: Polity Press. 
Cronin, M. (2011). Globalization. In M. Baker and G. Salsanha (eds.) Routledge Encyclopedia of Translation Studies,126129. London and New York: Routledge.

Davidson, B. (2000). The Interpreter as Institutional Gatekeeper: The Social-linguistic Role of Interpreters in SpanishEnglish Medical Discourse. Journal of Sociolinguistics 4(3): 379-504.

Erzurumlu, Ö. R. (2019). Interediting: Revealing the Dual Role of Staff Interpreters on Turkish News Channels. TransLogos, 2(1):68-84.

Ethelb. H. (2019). The Translator as Journalist: Getting Across the Ideological Intricacies of Translating News. Studies in Translation - Jordanian Translation Association, 5(1): 25-64.

Fairclough, N. (1995). Media Discourse. London and New York: Edward Arnold.

Fowler, R. (1991). Language in the News: Discourse and Ideology in the Press. London and New York: Routledge.

Hatim, B. \& Mason, I. (1990). Discourse and the translator. London and New York: Longman.

Hatim, B. \& Mason, I. (1997). The Translator as a Communicator. London: Routledge.

Hermans, T. (1996). Norms and the Determination of Translation. A Theoretical Framework. In R. Álvarez \& M. CarmenAfrica (eds.) Translation, Power, Subversion, 25-51. UK: Multilingual Matters Ltd.

Koskinen, K. (2000). Institutional Illusions: Translating in the EU commission. The Translator, 6(1): 49-65.

Lefevere, A. (1992). Translation, Rewriting and the Manipulation of Literary Fame. London and New York: Routledge.

Machin, D. (2008) News discourse I: Understanding the social goings-on behind news texts. In A. Mayr (ed.) Language and Power: An Introduction to Institutional Discourse, 90-114. London: Continuum.

Mohammed, H. \& Gunter, B. (2013). News Consumption and News Agenda in Egypt. In B. Gunter \& R. Dickinson (eds.) News Media in the Arab World. London and New York: Bloomsbury.

Orengo, A. (2005). Localising News: Translation and the "Global-Local" Dichotomy, Language and Intercultural Communication, 2(2): 168-187.

Palmer, J. \& Fontan, V. (2007). Our Ears and Our Eyes: Journalists and Fixers in Iraq, Journalism 8(1): 5-24.

Participant 1 (2016). Personal Interview. 15/03/2016.

Participant 2 (2016). Personal Interview. 23/03/2016.

Participant 3 (2016). Personal Interview. 02/04/2016.

Participant 4 (2016). Personal Interview. 03/05/2016.

Saldanha, G. \& O'Brien, S. (2013). Research Methodologies in Translation Studies. London and New York: Routledge.

Schäffner, C. (2004). Political discourse analysis from the point of view of translation studies. Journal of language and politics 3(1): 117-150.

Schäffner, C. (2015). Speaker positioning in interpreter-mediated press conference. Target 27(3): 422-439.

Schäffner, C. \& Bassnett, S. (eds.) (2010). Political Discourse, Media and Translation. Newcastle: Cambridge Scholars Publishing.

Tsai, C. (2005). Inside the Television Newsroom: An Insider's view of International News Translation in Taiwan. Language and Cultural Communication, 5(2): 145-153.

Valdeón, R. A. (2020). Journalistic translation research goes global: theoretical and methodological considerations five years on, Perspectives, 28(3): 325-338, DOI: 10.1080/0907676X.2020.1723273

Van Leeuwen, T. \& Wodak, R. (1999). Legitimizing immigration control: A discourse-historical analysis. Discourse Studies, 1(1): 83-118.

Williams, J. \& Chesterman, A. (2002). The Map: A beginner's guide to doing research in translation studies. Manchester: St Jerome Publishing.

Zanettin F. (2016). The deadliest error': translation, international relations and the news media. The Translator, 22(3): 303318. DOI: $10.1080 / 13556509.2016 .1149754$.

\section{Endnotes}

\footnotetext{
${ }^{1}$ In fact, Calzada-Pérez (2003, p.1) did not state 'social media', but "new means of communication (notably the Internet) and media (e.g. satellite and digital television)". This is because the term 'social media' has not been widely used as early as 2003 , but Calzada's wording can be taken as a pointer to 'social media'.
} 